\title{
Speech Act of Complaining: Socio-Pragmatic study of Complaint by Moroccan EFL Learners
}

\author{
Abdelfattah Laabidi \\ Sidi Mohamed Ben Abdellah, School of Arts and Humanities \\ Fes-Sais, Morocco \\ abdelfattah.laabidi@usmba.ac.ma \\ Prof Adiba Bousfiha \\ Sidi Mohamed Ben Abdellah, School of Arts and Humanities \\ Fes-Sais, Morocco \\ adiba.bousfiha@usmba.ac.ma
}

DOI: http://doi.org/10.36892/ijlls.v2i2.294

\begin{tabular}{ll}
$\begin{array}{l}\text { Received: } \\
\text { 01/05/2020 }\end{array}$ & Complaining as a speech act can occur in every conversation even \\
& unintentionally. The use of this speech act is culture specific. The expressions \\
\hline Accepted: & and strategies used to issue a complaint vary according to context, \\
20/05/2020 & interlocutors and to other socio-cultural variables. The present study \\
& investigates the complaint strategies of Moroccan higher education \\
& institutions EFL students. Data for the current study are collected from 37 \\
\hline Keywords: & second and third year students learning English as a Foreign Language $(E F L)$ \\
Socio-pragmatic & representing a population in Moroccan Higher Education embodied in \\
competence; & Moulay Ismail University, Meknes and who have managed to answer a \\
Complaining; & discourse completion test composed of five situational prompts. A quantitative \\
Discourse completion & design is used for the collection, the analysis and the interpretation of data. \\
test (DCT); Indirect & The data gathered are described and analyzed using descriptive statistics. The \\
strategies. & findings indicate that Moroccan EFL students use specific linguistic forms to \\
& make complaints regarding different social variables such as social distance, \\
& ranking and social power. They also imply that Moroccan EFL learners tend \\
& to use more indirect strategies in issuing their complaints along with some \\
& intimacy expressions that mark the specificity of the Moroccan culture as a \\
& positive politeness culture, par excellence.
\end{tabular}

\section{INTRODUCTION}

In the Longman Dictionary of Contemporary English, complaint is defined as a kind of irritation, dissatisfaction about something and/or someone. This entails that a complaint can be viewed as a reminder that the speaker has ignored the hearer's face and emotions (Mayor, 2009). Following Austin's (1962) and Searle's $(1969,1979)$ Speech Act Theory and their classifications, pragmatists have explored the actual forms and functions of different speech acts in different languages. As for complaint, Trosborg (1995) defines it as "an illocutionary act in which the speaker expresses his/her disapproval and negative feeling towards the state of affairs described in the proposition and for which he/she holds the hearer responsible, either directly or indirectly" (p. 311). In other words, whilst the speaker makes a complaint, rather than just expressing his/her censure or blame, $\mathrm{s} /$ he is aiming at asking the hearer to perform a corrective act to compensate for the loss of the speaker's face through apologizing. This, however, infers that the speech act of complaining includes both expressive and directive functions as suggested by (Trosborg, 1994). 
Given the fact that native English socio-pragmatic competence is strongly related to its context, being socio-pragmatically competent in this language is a challenge for EFL learners who are rarely exposed to the target culture (Thi and Yeh, 2020). Unfortunately, not much research is conducted in this respect. Therefore, the significance of this study lies in its ability to fill some hiatus in the field of socio-pragmatic studies in the Moroccan context. It sheds some light on the ongoing Moroccan EFL learner's development of socio-pragmatic competence in a scarily studied speech act which is complaining. Additionally, the importance of working on complaining as a speech act in the Moroccan context resides in the fact that the employment of adequate strategies and pre-strategies for complaining is a very functional skill for successful communication knowing that complaining is a very facethreatening act that menaces not only the hearer's face but also the speaker's one. Henceforth, a badly-chosen strategy for complaining could harm social relationships and cause long-term misunderstandings between the interlocutors. Moreover, since cultures have different interpretations and measures to weigh face; the issuing of the speech act of complaining could be challenging and even complicated for the speakers (Zhang, 2001). Thus, a sociopragmatic pragmatic study on complaining is as worthwhile and rewarding as the studies on other speech acts.

\section{LITERATURE REVIEW}

\section{Speech Act Theory}

In his endeavor to develop Speech Act theory, Searle (1977) thoroughly approaches Austin's (1962) classification of illocutionary forces and, henceforth, puts a new taxonomy for speech act. This new approach is based on four major directions of fit that are concerned with whether language is supposed to suit the reality, or the world is assumed to conform to language. These directions are: (a) word-to-world, (b) world-to-word, (c) the double direction of fit and (d) the null direction of fit. Using these four new directions as a new scale makes Searle (1977) distinguish between five different functions of language under which speech acts are performed. These functions, according to Eemeren and Grootendorst (1983), are: (a) saying how something is, (b) trying to get people to do something, (c) committing ourselves to doing something, (d) expressing sentiments or attitudes and (e) bringing about changes in reality.

The abovementioned functions of language correspond to the five categories of speech acts that Searle (1975) identified which are: (a) directives through which the speaker targets producing some effect like in requesting and demanding, (b) representatives in which the speaker is committed to the truth of the proposition expressed such as claiming, affirming and stating, (c) expressives that help the speaker express his/her attitude towards a state of affairs such as in apologizing and condoling, (d) commissives by which the speaker is committed to some future course of action as it is the case in promising and threatening, and finally (e) declaratives which actually make a change in the state of the world like declaring and appointing.

\section{The Speech Act of Complaining}

Complaining is regarded as an expressive speech act by which the speaker expresses his negative feelings towards negligence, worry, annoyance, crossness, denunciation, embarrassment, accusation, displeasure, guilt, dissatisfaction, fault or aggravation (Abdul Razzak and Jamil, 2016). According to Boxer (2010, p. 164), there are two basic structures for complaining; the first one is called direct complaining which is face-threatening and the second one is referred to as indirect complaining which attributes responsibility to the addressee for a specific offense as argued in Brown and Levinson's (1987). To put it 
differently, a direct complaint is directed to a hearer who is supposed to be responsible for making a mistake or causing an offense to the speaker. However, an indirect one as indicated by Gass and Neu (1995) can be an expression of dissatisfaction about oneself or something. Consequently, the hearer is not responsible for the mistake or the damage and in general the rationale behind it is seeking agreement or solidarity. Therefore, a clear cut line can be established between complaining and griping since in indirect complaints (griping) the hearer has no responsibility and s/he cannot remediate the mistake, and s/he cannot be held responsible for it.

As cited in Noisiri (2002), another classification of complaints is made by Trosborg (1994, p. 338) who classified complaints into four major categories that are, in turn, divided into eight groups or strategic forms; "no explicit reproach and it includes hints as a complaint strategy, disproval and it contains two strategies which are annoyance and ill consequences, accusation and it includes indirect accusations and direct accusations complaint strategies, and blame and it involves three main strategies namely modified blame, explicit blame (person) and explicit blame (behavior)" ( $\mathrm{p}, 4)$.

With regard to the aforementioned classifications of complaints strategies, a complaint can be issued employing three additional strategies as DeCapua (1998) would suggest; the request for repair which means that the speaker asks the hearer to compensate for or remediate the problem (check if you can fix this phone please), the justifications which in fact include factors or reasons used by the speaker to back up his/her request or demand for repair ( I need to travel right now, but the car is broken, you have to fix it soon) and criticism that entails an evaluation of the whole situation which directly threatens the hearer's face (Oh my god! you broke my car again, that's impossible).

It is evidenced that the learner's native culture has a tremendous impact on the learning of a second language (L2) and the pragmatic competence development in this language. In the Moroccan context, there are many proverbs and sayings which warn the Moroccans away from complaining a lot, such as (shakwa li Llah), "Our complaint is to Allah". Further, the Moroccan expression (Llah isamah), which means "In God's name tolerate...." or "put up with", is used pervasively in many contexts. Additionally, the Moroccan culture derives a lot of its values and traits from the Islamic doctrine which is the official religion in the country. According to Islam, complaining a lot can be seen as a symbol of weakness, lowness and abjectness. That's why it is advisable, in Islam, for believers to complain to Allah and not to people as in Surat Yussuf, verse 86 (Qala innama ashko baththee wahuzni ila Allah) meaning "I only complain of my grief and sorrow to Allah".

Furthermore, Islam is claimed to be the religion of tolerance since its beginning (Nafisi, 2018). This in fact explains the emphasis many verses and Hadiths stress upon tolerating mistakes and offenses made by others such as in Surat At-Taghabun 64, verse 14 (wain taAAfoo watasfahoo wataghfiroo fainna Allaha ghafoorun raheemun) meaning "But if you forgive and overlook and, cover up (their faults), Allah is forgiving, Most Merciful".

\section{METHODOLOGY}

The discourse completion test includes five distinctive situations that carry a variety of contexts and a mixture of different variables. The situations include different relationships of social power, distance and social ranking. For instance in situation 1, the relationship between the speaker and the hearer is a neighborhood relationship in which the power and ranking variables are equal. However, in situation 2 the relationship between the interlocutors is a neutral relationship between two strangers but from different age groups which means that the speaker (younger) may use a high degree of formality to formulate the complaint to an elder hearer. Whereas, in situations 3, 4 and 5 the relationship between the speaker and the 
hearer is a professional relationship (agent- client) that does necessarily require a high degree of formality.

To achieve the objectives of the present study, a quantitative method was adopted in the data collection, analysis and interpretation phase. The data collection was carried out using a discourse completion test which includes five complaint situations. As far as the sample selected for this study is concerned, it is composed of 37 second and third year students learning English as a Foreign Language (EFL) representing a population in Moroccan Higher Education embodied in Moulay Ismail University, Meknes. The selection of this sample is due to the availability of participants enrolled in the English department in this institution. Therefore, the selection of the sample is carried out using non-probability (convenience) sampling strategy. The use of the latter strategy allows reaching a large number of participants from the population and increases the representativeness of the sample. The research questions that the study sets out are the following:

- How do Moroccan EFL students' complain with respect to the semantic prompts that are included?

- Do social distance and the severity of the offense impact the production of complaints by Moroccan EFL learners?

\section{FINDINGS OF THE STUDY}

In reaction to complaint scenarios used in the discourse completion test, respondents used different strategies that can be grouped into eight major strategies using DeCapua (1998) and Trosborg (1994) classifications of complaints which are: hint such as (I have been queuing for 30 minutes uncle), annoyance (there is a serious problem with your connection service, it is very slow), negligence like in (I don't mind. if he is an old person, I will not say a word), warning such as in (If you don't do your homework next time I will punish you), modified blame like in (seriously, can't you offer better services to your clients? You should offer us good services, we pay you), explicit blame (behavior) for example (It is really strange that a famous restaurant like yours offer such bad service, you should be more careful), request for repair such as in (You should bring us clean knife and glasses, these are very dirty), justification like in (I really don't know how to say this, but I have an exam tomorrow and I need to concentrate a bit. Please turn down the music) and finally no answer.

Along with the aforementioned strategies employed by the respondents, many of them made use of mitigators to soften the force of the complaints and therefore save both the speaker and the hearers' faces. In this regard, it can be noticed that the respondents used a lot of titles such as Mr., Sir, Madame, and Miss to pave the way for making the complaints. They also used some intimacy or endearment expressions like dad, uncle, my neighbor, my sister, my brother, and dear students as a foreground for the complaint or what can be referred to as pre-complaint strategies.

As for the finding of the discourse completion test, as indicated in the table below, in situation one $40.45 \%$ of the respondents used an indirect strategy which is annoyance, $16.21 \%$ of them also used hint as the most indirect strategy, and $13.51 \%$ of them employed negligence, warning and justifications to issue the complaint. However, in situation two more than $72.97 \%$ of the respondents utilized negligence as a complaint strategy and only $13.51 \%$ of them made use of annoyance as a complaint strategy. Concerning situation three, $54.05 \%$ of the respondents used annoyance strategy to make their complaints and only $10.81 \%$ used a modified blame as a complaint strategy. As for situation four, a majority of $56.75 \%$ of the respondents made use of a request for repair as a complaint strategy and only $13.51 \%$ of them used annoyance strategy. Whereas, in situation $5,45.94 \%$ of the respondents employed warning to complain, $12.21 \%$ of them used annoyance strategy and $10.81 \%$ used negligence complaint strategy. 
Table 1. Complaint Strategies used by the Respondents in each Situation

\begin{tabular}{|c|c|c|c|c|c|c|}
\hline \multirow[t]{2}{*}{ Strategy } & \multicolumn{6}{|c|}{ Situation } \\
\hline & & 1 & 2 & 3 & 4 & 5 \\
\hline \multirow[t]{2}{*}{ Hint } & $\mathbf{F}$ & 6 & 3 & 1 & 3 & 2 \\
\hline & $\mathbf{P}$ & 16.21 & 8.10 & 2.70 & 8.10 & 5.40 \\
\hline \multirow[t]{2}{*}{ Annoyance } & $\mathbf{F}$ & 15 & 5 & 20 & 5 & 6 \\
\hline & $\mathbf{P}$ & 40.54 & 13.51 & 54.05 & 13.51 & 12.21 \\
\hline \multirow[t]{2}{*}{ Negligence } & $\mathbf{F}$ & 5 & 27 & 1 & 2 & 4 \\
\hline & $\mathbf{P}$ & 13.51 & 72.97 & 2.70 & 5.40 & 10.81 \\
\hline \multirow[t]{2}{*}{ Warning } & $\mathbf{F}$ & 5 & 0 & 0 & 2 & 17 \\
\hline & $\mathbf{P}$ & 13.51 & 0 & 0 & 5.40 & 45.94 \\
\hline \multirow{2}{*}{$\begin{array}{l}\text { Modified } \\
\text { blame }\end{array}$} & $\mathbf{F}$ & 0 & 0 & 4 & 0 & 0 \\
\hline & $\mathbf{P}$ & 0 & 0 & 10.81 & 0 & 0 \\
\hline \multirow{2}{*}{$\begin{array}{c}\text { Explicit } \\
\text { blame } \\
\text { (behavior) }\end{array}$} & $\mathbf{F}$ & 0 & 0 & 0 & 2 & 2 \\
\hline & $\mathbf{P}$ & 0 & 0 & 0 & 5.40 & 5.40 \\
\hline \multirow{2}{*}{$\begin{array}{l}\text { Request for } \\
\text { repair }\end{array}$} & $\mathbf{F}$ & 0 & 0 & 3 & 21 & 5 \\
\hline & $\mathbf{P}$ & 0 & 0 & 8.10 & 56.75 & 13.51 \\
\hline \multirow{2}{*}{ Justifications } & $\mathbf{F}$ & 5 & 2 & 6 & 0 & 0 \\
\hline & $\mathbf{P}$ & 13.51 & 5.40 & 16.21 & 0 & 0 \\
\hline \multirow[t]{2}{*}{ NA } & $\mathbf{F}$ & 1 & 0 & 2 & 2 & 1 \\
\hline & $\mathbf{P}$ & 2.70 & 0 & 5.40 & 5.40 & 2.70 \\
\hline \multirow[t]{2}{*}{ Total } & $\mathbf{F}$ & 37 & 37 & 37 & 37 & 37 \\
\hline & $\mathbf{P}$ & 100 & 100 & 100 & 100 & 100 \\
\hline
\end{tabular}

\section{DISCUSSION}

It can be noted from the complaint strategies used by the respondents in the DCT that they use more indirect strategies than direct ones as in situations 1,2 and 3 wherein the speakers use annoyance and negligence to react to the situations. The excessive use of indirect strategies can be a sign of politeness by which the speaker attempts to boost the degree of optionality for the speaker and therefore s/he mitigates the force of the illocutionary force of the complaint as in Blum-Kulka and Olshtain (1984). The argument is that the Moroccan culture is a positive politeness culture in which the speaker tends to make delicate complaints preceded by an introductory utterance/expression that paves the way for making the complaint. Through using indirect strategies, respondents tend to abide by the politeness principle, which establishes inherent links between indirectness and politeness and remoteness in approaching people, especially when it comes to face-threatening acts.

The results of the present study also suggest that Moroccan EFL learners employ more mitigation markers, which either intensify or soften the intended pragmatic force of an utterance, particularly when they wish to intensify the pragmatic force of an utterance; for example, the use of intimacy expressions such as my uncle, my sister, and my dad to react to most of the DCT's scenarios. In this realm and in conformity with Zhang's (2001), the findings of the discourse completion test confirm that Moroccan EFL learners' pragmatic competence is influenced by the local culture, this can be deduced from the way the respondents showed tolerance when it comes to an offense made by old people or by 
neighbors as it is the case in situation wherein the respondents used annoyance and negligence that are more tolerant strategies towards an offense.

From the findings of the current study, it can be noted also that the severity of the wrong (the degree or the intensity of the offense) is a crucial factor when speakers choose their complaint strategies. A case in point is the fifth situation when most of the respondents used warning as a complaint strategy; the use of warning in this situation can be explained by the belief that in Morocco not doing homework is not only a sign of laziness, but also an act of belittlement to the teacher. This entails that social factors and situational variables had a great impact on the choice of complaint strategies by the respondents.

\section{CONCLUSIONS, LIMITATIONS AND IMPLICATIONS}

The current study investigates the speech act of complaining used by Moroccan EFL learners in order to measure the impact of social distance and the perception of severity on the subjects' production of complaints. Data in this study is collected using a discourse completion test composed of five contextual prompts.

The first implication of the findings obtained from the data analysis shows that Moroccan EFL learners changed their complaint strategies by social distances between them and complainees and the severity of the offense in each prompt. The findings of the study also implied that Moroccan EFL learners use indirect complaint strategies which confirm the idea that the Moroccan culture is a positive politeness culture.

From the overall results, it can be implied also that Moroccan EFL learners use specific pre-complaint strategies such as the use of titles, mitigators and intimacy expressions. This idea denotes that Moroccan EFL learners are affected by the impact of their religion when issuing a complaint. Therefore, it can be concluded that culture is an impactful variable in the production of complaints and responding to them.

In this study, socio-pragmatic competence of complaining has been examined in relationship to social distance, raking and power. The research has been carried out using specific research design, sampling techniques, data collection instruments and scrupulous techniques for data analysis. Nevertheless, future research may approach the same topic from a different perspective. For instance, a questionnaire in Arabic can be useful to include more students from other departments and therefore cater for one of the limitations of this study which is the limited length of the population targeted.

\section{REFERENCES}

Austin, J. L. (1962). How to do things with words. New York: Oxford University Press.

Blum-Kulka, S., \& Olshtain, E. (1984). Requests and apologies: A cross-cultural study of speech act realization patterns (CCSARP). Applied linguistics, 5(3), 196-213.

Boxer, D. (2010). How to gripe and establish rapport. Speech act performance: Theoretical, empirical and methodological issues, 163-178.

Brown, P., Levinson, S. C., \& Levinson, S. C. (1987). Politeness: Some universals in language usage (Vol. 4). Cambridge university press.

DeCapua, A. (1998). The Transfer of Native Language Speech Behavior into a Second Language: A Basis for Cultural Stereotypes?. Issues in Applied Linguistics, 9(1).

Gass, S., \& Neu, J. (Eds.). (2009). Speech acts across cultures: Challenges to communication in a second language (Vol. 11). Walter de Gruyter. 
Mayor, M. (Ed.). (2009). Longman dictionary of contemporary English. Pearson Education India.

Nafisi, S. (2018). Tolerance in Islam. HTS Teologiese Studies / Theological Studies. 74. 10.4102/hts.v74i3.5145.

Noisiri, W. (2002). Speech Act of Complaint: Pragmatic Study of Complaint Behaviour between Males and Females in Thai. University of Sussex, 1-18.

Olshtain, E., \& Weinbach, L. (1987). 10. Complaints: A study of speech act behavior among native and non-native speakers of Hebrew. In The pragmatic perspective (p. 195). John Benjamins.

Razzak, S. F. A., \& Jamil, A. K. F (2016). A Pragmatic Study of Complaints. European Academic Research Vol. IV.

Searle, J. R., \& Searle, J. R. (1969). Speech acts: An essay in the philosophy of language (Vol. 626). Cambridge university press.

Searle, John R. "Indirect speech acts." Speech acts. Brill, 1975. 59-82.

Searle, J.R. (1977). Reiterating the differences: A reply to Derrida. Glyph, 198-208.

Searle John, R. (1979). Expression and meaning: Studies in the theory of speech acts.

Tran, T. M. T., \& Yeh, A. (2020). Keeping it Real: Vietnamese-English Pragmatic Representations in EFL Textbook. International Journal of Language and Literary Studies, 2(1), 1-20.

Trosborg, A. (1994). Interlanguage pragmatics: Requests, complaints, and apologies. Berlin: Mouton de Gruyter.

Zhang, De, "The speech act of complaining: a cross-cultural comparative study of Chinese and American English speakers" (2001). Retrospective Theses and Dissertations. 16213.

\section{$\underline{\text { AUTHORS' BIOS }}$}

Abdelfattah Laabidi is a high school teacher of English with the Moroccan ministry of education and a doctorate student in the research laboratory Discourse, Creativity and Society, English Studies at Sidi Mohamed Ben Abdellah, School of Arts and Humanities - Fes-Sais, Morocco.

Dr. Adiba Bousfiha is a Professor of linguistics and a member of the research laboratory Discourse, Creativity and Society; English Studies Sidi Mohamed Ben Abdellah, School of Arts and Humanities - Fes-Sais, Morocco. She has a PhD in Pragmatics. 


\section{APPENDIX \\ DISCOURSE COMPLETION TEST}

Dear respondents, we would be very grateful if you could possibly fill in this questionnaire. This questionnaire is a part of a study concerned with "Speech Act of Complaining: SocioPragmatic study of Complaint by Moroccan EFL Learners". All personal information will be kept private and confidential.

Situation 1: You are having an exam the next day and you are revising late at night. Unexpectedly, your neighbor has turned on the music very loudly. You feel very annoyed and cannot concentrate on your review. What would you do?

Situation 2: You are in a queue waiting to use an ATM machine for 30 minutes. When it is almost your turn, an elderly person tries to cut in line. What would you do or say?

Situation 3: You suffer from slow connection service and you call the company to make a complaint about that. What would you say in this situation?

Situation 4: You are having lunch in one of the most famous restaurants in your city but you find out that your knife and fork are not clean or healthy to use. What would you do or say?

Situation 5: You assigned a work to be done by your students. Surprisingly, a vast majority of them didn't take your request seriously and didn't do the work. What would you do or say? 